\title{
Pyridazine Derivatives and Related Compounds, Part 3 [1] Some Reactions with 4-Cyano-3(2 H)-pyridazinethione
}

\begin{abstract}
Ali Deeb*, Abdel Naby Essawy, Fathy Yasine, and Rida Fikry
Department of Chemistry, Faculty of Science, Zagazig University, Zagazig, Egypt

Z. Naturforsch. 46b, 835-837 (1991); received May 7/October 19, 1990

4-Cyano-5,6-diphenyl-3(2 H)-pyridazinethione, 3-Amino-5,6-diphenylpyridazine-4-carbonitrile

The reaction of 5-amino-3,4-diphenylthieno[2,3-c]pyridazine-6-carboxamide 2 with formamide, acetic anhydride and carbon disulphide yielded pyrimido $\left[4^{\prime}, 5^{\prime}: 4,5\right]$ thieno[2,3-c]pyridazin-4-one derivatives. Pyrimido[4,5-c]pyridazinethione and dithione derivatives were obtained by cyclocondensation of 3-amino-5,6-diphenylpyridazine-4-carbonitrile (8) with phenyl isothiocyanate and carbon disulphide, respectively. Tetrahydropyridazino[3,4-b]quinoline (11) was prepared by reaction of $\mathbf{8}$ with cyclohexanone in presence of zinc chloride.
\end{abstract}

In the course of a program directed to the synthesis of pyridazines annelated with various five and six membered heterocycles, we undertook the synthesis of thieno[2,3-c]pyridazine and its pyrimidine condensed system, which the pyrimidine ring is a frequent partner in polycyclic heterocyclic system of biological significance [2].

The direct route into this ring system proved to be the reaction of 5-amino-3,4-diphenyl[2,3-c]pyridazine-6-carboxamide (2) with formamide to yield 8,9-diphenylpyrimido $\left[4^{\prime}, 5^{\prime}: 4,5\right]$ thieno[2,3-c]pyridazin- $4(3 \mathrm{H})$-one $(3)$. The preparation of the required 5-amino-3,4-diphenylthieno[2,3-c]pyridazine-6-carboxamide (2) was accomplished using the procedure in the following equations (Scheme 1) and employed nucleophilic substitution by chloroacetamide at the 2-position of 4-cyano-5,6-diphenyl-3(2 H)-pyridazinethione (1) [3], with subsequent base promoted intermolecular ring formation [4].

Treatment of $\mathbf{2}$ with acetic anhydride under mild conditions afforded the 5-acetamido derivative (4), which underwent smooth cyclization to 2-methyl8,9-diphenylpyrimido $\left[4^{\prime}, 5^{\prime}: 4,5\right]$ thieno[2,3-c]pyridazin-4(3H)-one (5).

Condensation of 5 with 4-nitrobenzaldehyde furnished the corresponding 6-(4-nitro)styryl derivative (6).

Compound 2 was also reacted with carbon disulphide in the presence of potassium hydroxide to

\footnotetext{
* Reprint requests to Dr. A. Deeb.

Verlag der Zeitschrift für Naturforschung, D-7400 Tübingen $0932-0776 / 91 / 0600-0835 / \$ 01.00 / 0$
}

give 2-mercapto-8,9-diphenylpyrimido $\left[5^{\prime}, 4^{\prime}: 2,3\right]$ thieno[5,4-c]pyridazin-4(3 H)-one (7).

In a previous work [3], compound $\mathbf{1}$ was readily methylated with dimethyl sulphate; the resulting 3-methylthio derivative, readily reacted with ammonium acetate in acetic acid to give the 3-amino derivative (8), which represents a versatile building block for the synthesis of various fused pyridazines.

It was reported that the reaction of $o$-aminonitriles with carbon disulphide [5], aryl isothiocyanate [6] and cyclohexanone [7] yielded condensed pyrimidinethione and aminoquinoline derivatives.

Based on these results, it was found that compound 8 reacted with carbon disulphide to give 3,4-diphenylpyrimido[4,5-c]pyridazine-5,7(6 H,8 H)dithione (9), and reacts with phenyl isothiocyanate to give 3,4-diphenyl-7-phenylaminopyrimido[4,5-c]pyridazine-5 $(6 \mathrm{H})$-thione (10). The reaction of 8 with cyclohexanone in presence of one molar equivalent of $\mathrm{ZnCl}_{2}$ leads to a 1:1 complex of the expected amino derivative $\mathbf{1 1}$ and zinc chloride. 5-Amino-3,4-diphenyl-6, 7,8,9-tetrahydropyridazino[3,4-b]quinoline (11) was liberated by treatment of this complex with alkali (Scheme 2).

The structures of compounds 1-11 were established on the bases of their analytical and spectral data (see Table I).

\section{Experimental}

Melting points are uncorrected. ${ }^{1} \mathrm{H}$ NMR spectra were recorded on a Hitachi Perkin-Elmer Va 60 spectrometer with TMS as an internal stan- 